\title{
Business, Commerce and the Global Financial System
}

\author{
Meg Elkins and Liam J.A. Lenten
}

\begin{abstract}
Commercial practices are being re-defined by disruptive innovations that are opening up new global and local markets. This chapter examines how changing technologies are creating new opportunities for entrepreneurs in both the developing and developed world. In the developing world, micro-finance and mobile technologies are linking the vulnerable to markets. In the developed world long-held monopolies in the banking, transport, and hotel industries are now subject to a more competitive market with the rise of new platforms such as the sharing economy, crypto-currencies, and crowd funding.
\end{abstract}

Keywords Market access - New financial platforms - Increased competition

\section{Introduction}

Individuals and firms previously denied opportunities to participate in the market economy are integrating steadily into the global marketplace through the increased availability of information from the internet and mobile technologies. Micro-finance has given those in the developing world access to credit and micro-enterprises giving the developing world access to the market. In the developed world, the sharing economy, crypto currencies and crowdfunding are disrupting established financial market intermediaries. Internet access and mobile technologies play a significant role in how agents can communicate and interact, particularly in relation to institutions. Intermediaries and asymmetric information are becoming less significant as information and new financial platforms have the capacity to disrupt traditional networks.

\author{
M. Elkins (ه) \\ RMIT University, Melbourne, Australia \\ e-mail: meg.elkins@rmit.edu.au \\ L.J.A. Lenten \\ La Trobe University, Melbourne, Australia \\ e-mail: 1.lenten@latrobe.edu.au
}

(C) The Author(s) 2016

M.E. Robertson (ed.), Communicating, Networking: Interacting,

SpringerBriefs in Global Understanding, DOI 10.1007/978-3-319-45471-9_6 


\section{Micro-Finance-Connecting the Poor to Markets}

Micro-finance bridges the gap between the banks and the lenders of money to people in the developing world. These firms have been able to provide small unsecured loans to people who would be ineligible for loans from traditional financial institutions (Yunus 1999). Micro-finance refers to micro-credit, micro-savings, micro-insurance and money transfers for small amounts of money from (USD) $\$ 50$ to $\$ 1000$ (Van Rooyen et al. 2012; Yunus 1999). These loans have been attributed to helping micro-entrepreneurs create business and increase income as well as contribute to an improvement in well-being to the life of the poor (Van Rooyen et al. 2012). The Grameen Bank is attributed with the introduction of micro-finance in Bangladesh in the 1970s. It now provides loans valued at \$2 billion annually to over 30 million members (Khandker and Samad 2014).

In essence, micro-finance has been able to connect those normally excluded from local and global markets (due to poor asset wealth) to funds many assume essential to get ahead in life. Overwhelmingly, women have benefited the most from gaining access to these funds resulting in greater employment generation, increased income generation and significant improvement in social indicators these indicators include the Human Development Index (HDI), primary school enrolment and health indicators (Khandker 2005; Van Rooyen et al. 2012). Empowering women with businesses to spend their incomes on education and health for their families benefits the individual family most directly, but also has broader ramifications for their society, as it also develops the social and human capital for that society. The establishment of micro-enterprises financed through the micro-credit system creates a more socially-interactive community for the poor to participate in the broader economy.

\section{Mobile Technologies-Connecting Local Businesses to Global Markets}

The proliferation of mobile technologies in the developing world has created opportunities for small landholders. Mobile phone networks have provided a more affordable alternative to landlines, which were previously too expensive for villages in remote and regional areas due to the high cost of infrastructure (Dannenberg and Lakes 2013). Farmers with small landholdings have been among the main beneficiaries of the introduction of mobile technologies due to increased access to market information. There are two reasons for this: firstly, village markets are characterised traditionally by asymmetrical information whereby intermediaries or traders are more aware of prices in the central markets. In the past, asymmetrical information has led to low productivity and low farm incomes. In the case of 
interventions in areas of Kenya, mobile phones have resulted in improvements in food security and farm incomes (Ogutu et al. 2014). Secondly, the introduction of these technologies adjusts the power balance between small-landholder and agricultural intermediaries. Mobile technology allows for immediate access to up-to-date market information, and also provides the farmer with direct access to payments both for paying for agricultural resources, such as fertiliser and seeds; as well as receiving payments for their crops. In rural Kenya, the mobile payment service M-Pesa has been adopted widely by the farmers in the export market for fruit and vegetables (Dannenberg and Lakes 2013). Mobile phones allow farmers to deal directly with exporters, circumventing the need for intermediaries, and ostensibly this gives them access to the global market. Farmers are less likely to accept unfavourable prices for their crops, thus improving their bargaining power (Tadesse and Bahiigwa 2015). Mobile phones also provide important information in regards to best-practice farming, determining best timing of when to plant and when to harvest, as well as market demand for particular crops. All this provides direct benefits to productivity, which should result in higher levels of farm income.

\section{The Changing Role of Markets}

There is an increasing recognition of the role and importance of communication, networks and groups in the determination of economic outcomes-employment, income and wealth among these-demonstrative of the shift away from the traditional rational individual (homo economicus) assumption that underpins many long-standing models in the discipline.

As both a wonderful reference tool and literature survey, Paul Frijters (Queensland) and Gigi Foster (UNSW) deal with these themes in intimate detail in their recent book (Frijters and Foster 2013) Economic Theory of Greed, Love, Groups and Networks. Tellingly, against the background of the basic economic activity of trade, they describe networks as: “.... a crucial component of the modern economic system of production and exchange" (p. 5), with Winters et al. (2004) making a useful extension to this. They then proceed to invoke microeconomic theoretical modelling (see pp. 349-396) to extend on several in-text examples.

Frijters and Foster proceeded to cite numerous specific examples of similarlythemed studies in the literature. Some focus on topics that are highly-aligned with identifiable fields within the discipline; such as political economy, public, experimental, development, finance, education, industrial organisation, management, monetary, labour, behavioural, social science and agriculture-see, for instance, Becker (1974) and Caskie (2000) as examples of the latter two. Others are included that cross-over into other (largely exclusive) disciplines, such as psychology, biology, and reproductive science. 


\section{The Sharing Economy}

The rise of the 'sharing economy' is one of the clearest comparisons between developed and developing nations, with respect to the effect of communication technology on everyday practice. The sharing economy has the potential to disrupt the way we traditionally exchange goods and services and function as markets. This technology is underpinned by the recent growth of application-based programs on mobile communication devices that have decreased the transaction costs of exchange. Specific examples of such applications, and how they have changed the business landscape of selected industries, have already been researched and discussed in the business studies literature; such as the accommodation service AirBnB (Zervas et al. 2015) and the ride-sharing system Uber (Anderson 2014); while more generally, (Belk 2014) reinforces how such innovations force us to re-think the old adage 'you are what you own'. The dynamic pricing model for companies such as Uber provides incentives for those with capital assets (cars) to respond to increases in demand.

In the developed world, such technology plays a significant part in collaborative consumption, essentially between strangers, thus stimulating the volume of everyday practices that typically people would otherwise often undertake in partnership with existing friends, colleagues, associates or family members (ie. within their own network of individuals). Rising incomes in the past few generations have occurred contemporaneously with losses of networks and a sense of communityconsistent with other social indicators, such as declining birth rates (Ahn and Mira 2002), smaller household sizes (Australian Bureau of Statistics 2010) and an increasing incidence in mental illness (World Health Organization 2015). Under such trends, these applications have served the potential to fill the void of community breakdown in expanding non-technology collaborative consumption outcomes, which is arguably forecasted to become increasingly necessitated by dwindling global levels of natural resources relative to population.

By stark contrast, in the developing world, with far less (both) human and physical capital, but greater social capital, end users and service providers are typically already connected and have an intimate sense of each other's preferences; while the role of trust is clearly critical. Thus, the traditional levels of collaborative consumption have not reduced significantly during the modern era in the first instance. In this environment, the uptake and impact of these applications is expected to be somewhat more limited, at least in the short-term.

\section{Crypto-Currencies-Financial Markets Without Institutions}

One of the next frontiers in global financial systems is that of crypto-currencies. The best known of these currencies is the Bitcoin, which offers alternate methods of exchange without the use of financial institutions. Bitcoin is a system of exchange 
that is not administered by a single institution, government or country for its existence (Sadeghi 2013). The software underlying its creation established that Bitcoins would be able to be 'mined' slowly and steadily until there was 21 million units in circulation (Cheung et al. 2015). This crypto-currency uses an innovative cryptography called a blockchain; this is a public ledger that is effectively a permanent, incorruptible and irreversible trace of all Bitcoin transactions. In traditional transactions, we use banks to determine all transactions and account balances. The uniqueness of Bitcoin is that an intermediary is no longer required - all individuals consult the most recently-updated public ledger. The Bitcoin revolution is puzzling to economists as intrinsically there is no value of exchange (Yermack 2013). However, its newness and untapped potential could see such transactions be the new protocol of exchange. Bitcoin has the potential to be a revolutionary peer-to-peer platform, akin to the disruption that Skype had on telecommunications; alternatively, this could be merely a passing fad. The biggest barrier to bitcoin and crypto-currencies is the relationship of trust, particularly as these currencies are not managed by a single authorised institution or company.

\section{The Role of the Crowd in the Entrepreneurial Space}

Crowdfunding represents another disruptive method by which the internet is offering a new way of engaging the community to support new businesses and ideas. The entrepreneur raises funds by making an open call on the internet collecting small amounts of money from a large number of investors. The crowd, in turn, has a closer relationship with the firm both as consumers and investors (Belleflamme et al. 2014). The equity (profits) of the business is then distributed back to the funding 'crowd'. Kickstarter, Fundable, and Indiegogo are the most well-known of the crowdfunding sites. The pebble 'smart watch' is a case whereby venture capital initially rejected the project but a Kickstarter fund was able to evidence demand for the good and an initial request for US\$100,000 for 100 watches resulted in over \$US 10 million in pledges (Agrawal et al. 2014). The crowdfunding also serves as a marketing tool to create awareness of products in their development stages (Mollick 2014).

\section{Conclusion}

Integration into the marketplace - encouraging entrepreneurial activities in previously untapped markets-allows for global expansion and connectedness. Technological advances are creating new business platforms and financial innovations that are disrupting traditional institutions. Mobile technologies are benefitting consumers and producers in both the developed and developing world. Small landowners are able to make greater profits on their produce by having better access 
to information in the developing economies. New business platforms are making use of scarce and idle resources such as an individual's home (AirBnB) and car (Uber) with peer-to-peer networks facilitating market transactions in the developed world. The benefit for the consumer is the reduced cost of goods and services. The benefit for the economy is that ordinary individuals are able to leverage businesses off everyday assets, which increases competition among traditional monopolies.

Open Access This chapter is distributed under the terms of the Creative Commons Attribution 4.0 International License (http://creativecommons.org/licenses/by/4.0/), which permits use, duplication, adaptation, distribution and reproduction in any medium or format, as long as you give appropriate credit to the original author(s) and the source, provide a link to the Creative Commons license and indicate if changes were made.

The images or other third party material in this chapter are included in the work's Creative Commons license, unless indicated otherwise in the credit line; if such material is not included in the work's Creative Commons license and the respective action is not permitted by statutory regulation, users will need to obtain permission from the license holder to duplicate, adapt or reproduce the material.

\section{References}

Agrawal, A. Catalini, C. and Goldfarb, A. 2014. 'Some Simple Economics of Crowdfunding' in Lerner, J. and Stern, S. (eds.) Innovation Policy and the Economy, Volume 14. NBER: University of Chicago Press, 63-97.

Ahn, N. and Mira, P. 2002. 'A Note on the Changing Relationship between Fertility and Female Employment Rates in Developed Countries'. Journal of Population Economics, 15(4), 667-682.

Anderson, D. N. 2014. “"Not Just a Taxi”? For-Profit Ridesharing, Driver Strategies and VMT". Transportation, 41(5), 1099-1117.

Australian Bureau of Statistics 2010. 2009-10 Year Book Australia.

Becker, G. 1974. 'A Theory of Social Interactions'. Journal of Political Economy, 82(6), 1063-1091.

Belk, R. 2014. 'You are what you can Access: Sharing and Collaborative Consumption Online' Journal of Business Research, 67(8), 1595-1600.

Belleflamme, P., Lambert, T. and Schwienbacher, A. 2014. 'Crowdfunding: Tapping the Right Crowd'. Journal of Business, 29(5), 585-609.

Caskie, P. 2000. 'Back to Basics: Household Food Production in Russia'. Journal of Agricultural Economics, 51(2), 196-209.

Cheung, A., Roca, E. and Su, J.-J. 2015. 'Crypto-currency Bubbles: An Application of the Phillips-Shi-Yu (2013) Methodology on Mt. Gox Bitcoin Prices'. Applied Economics, 47(23), 2348-2358.

Dannenberg, P. and Lakes, T. 2013. 'The Use of Mobile Phones by Kenyan Export-orientated Small-scale Farmers: Insights from Fruit and Vegetable Farming in the Mt. Kenya Region'. Economia Agro-Alementare, 15(3), 55-76.

Frijters, P. and Foster, J. 2013. Economic Theory of Greed, Love, Groups and Networks. Cambridge: Cambridge University Press.

Khandker, S. R. 2005. 'Microfinance and Poverty: Evidence Using Panel Data from Bangladesh'. World Bank Economic Review, 19(2), 263-286.

Khandker, S. R. and Samad, H.A. 2014. 'Dynamic Effects of Microcredit in Bangladesh'. The World Bank, Development Research Group, Working Paper, no. 6821. 
Mollick, E. 2014. 'The Dynamics of Crowdfunding: An Exploratory Study'. Journal of Business Venturing, 29(1), 1-16.

Ogutu, S. O., Okello, J. J. and Otieno, D. J. 2014. 'Impact of Information and Communication Technology-Based Market Information Services on Smallholder Farm Input Use and Productivity: The Case of Kenya'. World Development, 64, 311-321.

Sadeghi, A. 2013. Financial Cryptography and Data Security, 17th International Conference, FC 2013 Okinawa, Japan, April 1-5.

Tadesse, G. and Bahiigwa, G. 2015. 'Mobile Phones and Farmers' Marketing Decisions in Ethiopia'. World Development, 68(4), 296-307.

Van Rooyen, C., Stewart, R. and de Wet, T. 2012. The Impact of Microfinance in Sub-Saharan Africa: A Systematic Review of the Evidence. World Development, 40(11), 2249-2262.

Winters, L., McCulloch, N. and McKay, A. 2004. 'Trade Liberalization and Poverty: The Evidence so Far'. Journal of Economic Literature, 42(1), 72-115.

World Health Organization. 2015. Mental Health Atlas 2014.

Yermack, D. 2013. 'Is Bitcoin a Real Currency? An Economic Appraisal'. NBER Working Paper No. 19747.

Yunus, M. 1999. Banker to the Poor: Micro-lending and the Battle against World Poverty. New York: Public Affairs.

Zervas, G., Proserpio, D. and Byers, J. 2015. 'The Rise of the Sharing Economy: Estimating the Impact of AirBnB on the Hotel Industry'. Boston University, School of Management, Research Paper No. 2013-16. 